\title{
Developmental delay in early childhood is associated with visual-constructive skills at school age in a Brazilian cohort
}

\author{
Luciane da Rosa Piccolo ${ }^{1 *}$, Joice Dickel Segabinazi ${ }^{1}$, Olga Garcia Falceto², Carmen Luiza Correa Fernandes ${ }^{3}$, \\ Denise Ruschel Bandeira ${ }^{1}$, Clarissa Marceli Trentini ${ }^{1}$, Claudio Simon Hutz ${ }^{1}$ and Jerusa Fumagalli Salles ${ }^{1}$
}

\begin{abstract}
We investigated differences in IQ and visual-constructive skills in school-age children evaluated as developmentally delayed or typically developed in early childhood. Sixty-four participants from a Brazilian cohort were evaluated in IQ (Wechsler Abbreviated Scale of Intelligence) and tasks of visual-spatial memory and visual-constructive skills through the Benton Visual Retention Test (BVRT) at school age. Neuropsychomotor development at 4 years of age was measured by Denver II. Developmentally delayed children showed lower IQs, lower scores, and more errors in copy and memory BVRT tasks when compared to typically developed children. Delay in neuropsychomotor development in early childhood may affect the subsequent cognitive development of children.
\end{abstract}

Keywords: Visual-spatial memory, Visual-constructive skills, Neuropsychomotor development, Children development

\section{Background}

The nature of child development is essentially cumulative, and therefore, the first years of life are the basis for further development (Ali, 2013; Allen \& Kelly, 2015). Child development is dynamic and involves the maturation of interrelated systems: cognitive, physical, and social-emotional skills (Casey et al. 2005). Early childhood is a time marked by rapid physical and neurological development and requires nutrition, stimulation, and appropriate health care for children to reach their full potential in terms of academic achievement and potential future earnings (Greenough \& Black, 2013).

In general, children are referred to centers of treatment and diagnosis due to developmental delays, learning disabilities, or social interaction problems perceived by parents, teachers, or other professionals who follow the children into their routine. There are instruments to evaluate behavior and cognitive functioning in school-age children, including tasks with words and numbers, as at that age they are already able to

\footnotetext{
* Correspondence: lucianepiccolo@gmail.com

${ }^{1}$ Departamento de Psicologia, Universidade Federal do Rio Grande do Sul (UFRGS), Rua Ramiro Barcellos, 2600, 90035-003 Porto Alegre, RS, Brazil Full list of author information is available at the end of the article
}

understand language's codes (Prelock et al. 2008). On the other hand, neuropsychomotor assessment is the main approach to evaluate cognitive functioning in early childhood, since those skills are developing faster in this phase, while the understanding of symbols is just starting (Theuer \& Flores-Mendoza, 2003). The term "neuropsychomotor development" comprises motor skills, adaptation, socialization, and language (Dornelas et al. 2015; Le Boulch, 2001).

Neuropsychomotor development is crucial, since children develop language and other complex mental processes by the relationships they establish with the environment and active exploration through the manipulation of objects, the repetition of actions, and body self-control (Iverson, 2010; Levey \& Polirstok, 2011). Progress in child development can be observed by the expression of initial motor acts and behaviors expected for each age getting successively more complex, according to the gradual maturation of the nervous system (Casey et al., 2005). Moreover, while children advance in independence and coordination, they become able to separately control each motor sequence and gradually coordinate these independent movements, making them more complex (Corso, 2007). 
Throughout the development, fine motor skills merge with visual skills, allowing the assessment of problem solving based on visual-motor skills, an essential function of intellectual development (Accardo et al. 2008; Lipkin \& Schertz, 2008). Visual-constructive skills require the coordination of fine motor skills with visual-spatial abilities and include not only the perception of objects and execution of movements but also planning and mental organization, essential capabilities to the development of more complex cognitive skills (Lanca et al. 2003).

Delayed neuropsychomotor development has a negative impact on children's interactions in their environment, what may cause deficits in their performance of daily activities and further changes in the functioning of critical systems for learning, memory, and general reasoning (Hernandez \& Caçola, 2015; Wendt et al. 1984). It was estimated that about 200 million children (up to 5 years old) across the world present delays in their development (Grantham-McGregor et al., 2007). In Brazil, it was reported that $3.3 \%$ of the 3869 two-year-old children screened positive for suspected developmental delay (de Moura et al., 2010). Longitudinal studies have reported the relationship between neuropsychomotor delays and deficits on intelligence (Davis et al. 2007; Murray et al. 2007), language (Amaral et al. 2005), academic achievement (Taanila et al. 2005), and socioemotional skills (Bart et al. 2007). Individuals who have marked delays in reaching developmental milestones in early childhood periods are at higher risk for a subsequent diagnosis of learning disability or intellectual deficit (Murray et al., 2007; Murray et al., 2006; Taanila et al., 2005).

During early childhood, especially due to the sharp brain neuroplasticity, children's experiences may have long-lasting effects on the development of mental processes (Greenough \& Black, 2013; Skaliora, 2002). In this sense, it is important to investigate the cognitive processes since early childhood so that delays or difficulties can be predicted and effective interventions can be planned. Based on this assumption, this study compared the performance of children reported as developmentally delayed at 4 years old and typically developed children on IQ, visual-spatial memory, and visual-constructive skills at school age.

\section{Methods}

\section{Participants}

Participants were children who were recruited as a part of a larger birth cohort study on development in childhood. A detailed explanation of the objectives of the longitudinal study and the recruitment of participants can be found at Piccolo et al. (2012). The participant families belong to an area covering 18,000 people, approximately, and are assisted by three health units of the "Conceição
Hospital Group" (Porto Alegre, RS, Brazil). Through the records of the births in that hospital from December 1998 to December 1999, the families were invited to participate in the study. All the families that have agreed to participate in that study were included. The longitudinal study had four data collection phases: at children's 4 months of age $(N=146)$ and then when children were $2(N=126), 4(N=126)$, and $9 / 10$ years old $(N=70)$.

For the present study, data were analyzed from a sample of 64 children (49.2\% male), participants for whom complete data were available on all variables assessed. At 4 years of age, children participating in this study were assigned as the developmentally delayed (DD) group $(N=39)$ or the typically developed (TD) group $(N=25)$ (Table 1$)$ after neuropsychomotor assessment (Denver II). Table 1 shows the demographics of the sample, confirming that both groups showed equivalent sociodemographic characteristics. By the time of the visual-constructive skill evaluation, children's age range from 9.7 to 11.8 years $(M=9.53$ years, $\mathrm{SD}=1.52$ ). All participants were students from fourth to fifth grade from public schools, and their primary caregiver was their own mothers. The children were mostly from low socioeconomic status families, with average family income of about four minimum wages $(M=3.95, \mathrm{SD}=2.5$; Table 1$)$. In the interviews conducted by family therapists, families have reported that children have received no treatments since they were evaluated with Denver II.

\section{Instruments}

When the children were 4 years old, family therapists conducted interviews with participating families and collected socioeconomic data (socioeconomic status index) (MARPLAN, 2008), family functioning (Global Assessment of Relational Functioning (GARF)), and maternal mental health (Self-Reporting Questionnaire (SRQ-20)) scales. The GARF scale (Cronbach's alpha = .89; Falceto et al. 2000) evaluates whether the family meets the affective and operational needs of its members in a fivepoint Likert scale ( $1=$ dysfunctional; $5=$ satisfactory functioning). In addition, SRQ-20 (Mari \& Williams, 1986) was used to evaluate maternal emotional and physical symptoms associated with psychiatric disorders (Cronbach's alpha $=.86$ ). This scale consists of "yes or no" questions, and significant psychiatric morbidity is diagnosed when seven or more of the listed symptoms are reported.

The Denver II test (Drachler et al. 2007; Frankenburg et al. 1992) was used to evaluate the children's neuropsychomotor development. This test was designed for evaluating children from birth to 6 years of age and consists of 125 items that assess the child's socialization aspects within and outside the family environment; fine 
Table 1 Sample demographics $(N=64)$

\begin{tabular}{|c|c|c|c|}
\hline & \multicolumn{3}{|l|}{ Groups } \\
\hline & Developmentally delayed $(N=39)$ & Typically developed $(N=25)$ & \\
\hline & $M(S D)$ or $\%(N)$ & $M(\mathrm{SD})$ or $\%(N)$ & $p$ \\
\hline Age (years) & $9.72(0.46)$ & $9.89(0.33)$ & .559 \\
\hline Years of education & $3.54(0.64)$ & $3.71(0.62)$ & .384 \\
\hline Female & $41 \%(16)$ & $60 \%(15)$ & .260 \\
\hline Male & $59 \%(23)$ & $40 \%(10)$ & .317 \\
\hline SES & $3.63(0.75)$ & $3.36(0.95)$ & .378 \\
\hline Maternal mental health (SRQ) (early childhood) & $4.75(3.10)$ & $4.35(3.81)$ & .439 \\
\hline Family functioning (GARF) (early childhood) & $67.95(16.38)$ & $71.46(16.53)$ & .566 \\
\hline Maternal mental health (SRQ) (school age) & $6.64(5.09)$ & $5.10(3.65)$ & .134 \\
\hline Family functioning (GARF) (school age) & $64.51(19.66)$ & $69.86(17.19)$ & .230 \\
\hline
\end{tabular}

SES socioeconomic status (income and parental education index), SRQ Self-Reporting Questionnaire, GARF Global Assessment of Relational Functioning

motor skills (eye/hand coordination, small object manipulation); gross motor skills (body motor control, sit, walk, jump); and language (sound production, ability to recognize, understand, and use the language). These items are recorded through direct observation of the children, and for some items, it is required to ask the mother if the children are able to perform a certain task or not. Taking into account the results of those evaluations, the examiner concluded if the child was typically developed or if he/she presents a developmental delay, comparing the child's development to what is expected of his/her correspondent age. In this study, the $90^{\text {th }}$ percentile of the Denver II test was the cutoff point to classify children as developmentally delayed, as recommended in the manual (Frankenburg et al., 1992).

At school age (9-10 years old), children were evaluated in IQ, visual-spatial memory, and visual-constructive skills and families answered the SRQ-20 and GARF again. After authorization from schools and parents/guardians (by signing the informed consent), the evaluation was performed with each child individually. There were two sessions (one for assessment of IQ and another for evaluation of other cognitive functions) with approximately $1 \mathrm{~h}$ each, in a school room prepared for testing. IQ was evaluated by composite of the Vocabulary and Matrix Reasoning subtests from the Wechsler Abbreviated Scale of Intelligence (WASI) (Trentini et al. 2014). This instrument was developed for use in individuals from 6 to 89 years old and consists of four subtests-Vocabulary, Cubes, Similarities, and Matrix Reasoning-that assess cognitive aspects, such as verbal knowledge, visual information processing, spatial and non-verbal reasoning, and fluid and crystallized intelligence (Yates et al., 2006). The WASI may be comprised of two or four subtests, with the two-subtest version (Vocabulary and Matrix Reasoning composite) yielding only a Full Scale IQ estimate (Groth-Marnat, 2009). Subtest raw scores are converted to $T$ scores by way of tables in the manual. $T$ scores can then be converted to either FSIQ-4 (all four subtests administered) or FSIQ-2 (only Vocabulary and Matrix Reasoning administered) standard scores, percentiles, and age equivalents.

The Brazilian version (Salles et al. 2016; Segabinazi et al., 2013) of the Benton Visual Retention Test (BVRT) was used to assess visual-constructive abilities (copy task) and visual-spatial memory (memory task). The A (memory) and the $\mathrm{C}$ (copy) administration forms were combined with the $\mathrm{C}$ and the D stimulus forms, respectively. For the memory task, each of the 10 slides was presented to the participants for $10 \mathrm{~s}$, and immediately after that, the memory image was requested. For the copy task, children were asked to copy another 10 figures presented. The total execution time, total correct and error scores, and the types of errors (distortions, omissions, perseverations, rotations, and misplacements) for both copy and memory tasks were analyzed.

\section{Statistical analyses}

Sample characteristics such as age, education and socioeconomic status (SES), family functioning and maternal mental health at early childhood, and school age were analyzed using descriptive statistics and group comparison tests (chi-squared and ANOVAs, $p<.05$ ). Based on the Denver II scores (90 percentile), children were assigned to $\mathrm{DD}$ or TD. Then, the performance on IQ and BVRT tasks was compared between those groups. As the neurocognitive task variables did not show a normal distribution, we compared those outcomes using non-parametric tests (Mann-Whitney, $p<.05$ ). Finally, chi-squared tests were performed to compare the frequency of children who presented scores below the milestone for their age $(p<.05)$. Statistical analyses were performed using SPSS 23 software. 


\section{Results}

\section{IQ differences between groups}

When analyzing the whole sample $(N=64)$, a significant difference in IQ scores between groups was observed. The DD group showed lower IQ scores compared to TD $\left(F(1,62)=6.018 ; p=.017 ; \eta^{2}=.09\right)$. Taking into account that intellectual deficits could bias the interpretation of neuropsychological performance, children with IQ scores under 70 were removed $(N=8)$ from further comparative analysis between groups. All of them were from the DD group. The difference between groups for the socioeconomic variables remained statistically nonsignificant, and the IQ difference between DD and TD was not significant anymore.

\section{Visual-spatial memory and visual-constructive skill differences between groups}

There were significant differences between groups in both the BVRT copy and memory tasks (Table 2 and Fig. 1). Figure 1 illustrates the groups' statistical significant differences in performance: DD were less accurate and made more errors as distortions and misplacements for both copy and memory tasks in relation to TD. In addition, significant differences between groups were observed in omissions, perseverations, and rotation for the BVRT memory task: DD committed more of those types of errors. Finally, it was observed that the DD were faster to execute the copy task but slower in performing the memory task when compared to TD (this last difference showed a very small effect size-see Table 2).

\section{Classification according to BVRT normative milestones}

Finally, it was observed that DD scores in both copy and memory tasks were more frequently classified under the milestone for their age (according to the BVRT normative milestones), when compared to the TD. In the copy task, $15.4 \%$ of DD performed below the milestone in the correct scores and $20.5 \%$ in the error scores, whereas $12 \%$ of TD were below the milestone for both correct and error scores. The difference was not statistically significant for copy tasks, but it was significant for memory tasks: correct score difference $X^{2}(2, N=56)=$ $4.24, p=.012$, and error score difference $X^{2}(2, N=56)=$ $4.41, p=.038$. In the memory task, $15.4 \%$ of DD have performed below the milestone for both correct and error scores, whereas no children from the TD group showed scores below that limit.

\section{Discussion}

The findings from this study indicated that the neuropsychomotor development delay perceived at 4 years of age was associated with IQ and the development of visual-spatial abilities later, at school age. The skills developed in early childhood seem to be fundamental to

Table 2 BVRT performance by groups (Mann-Whitney test)

\begin{tabular}{|c|c|c|c|c|c|c|}
\hline & \multicolumn{2}{|l|}{ Groups } & \multirow[t]{3}{*}{$U$} & \multirow[t]{3}{*}{ Z } & \multirow[t]{3}{*}{$p$} & \multirow[t]{3}{*}{$\eta^{2}$} \\
\hline & $\mathrm{DD}(N=31)$ & $\mathrm{TD}(N=25)$ & & & & \\
\hline & Mdn (Range) & Mdn (Range) & & & & \\
\hline \multicolumn{7}{|l|}{ BVRT_copy task } \\
\hline Correct score & $8.72(5-10)$ & 10 & 80.5 & -5.427 & $<.001$ & .53 \\
\hline Error score & $1.39(0-5)$ & 0 & 80.5 & -5.427 & $<.001$ & .53 \\
\hline Distortions & $1.22(0-4)$ & 0 & 80.5 & -5.428 & $<.001$ & .53 \\
\hline Omissions & 0 & 0 & 356.5 & 0 & 1 & 0 \\
\hline Perseverations & 0 & 0 & 356.5 & 0 & 1 & 0 \\
\hline Rotations & 0 & 0 & 356.5 & 0 & 1 & 0 \\
\hline Misplacements & $0.11(0-1)$ & 0 & 138.0 & -4.598 & $<.001$ & .38 \\
\hline Time (minutes) & $7.36(4-12)$ & $9.87(6-23)$ & 157.0 & -3.666 & $<.001$ & .24 \\
\hline \multicolumn{7}{|l|}{ BVRT_memory task } \\
\hline Correct score & $5.44(4-8)$ & $5.67(3-8)$ & 175.5 & -3.268 & .001 & .19 \\
\hline Error score & $7.22(4-11)$ & $4.83(4-5)$ & 156.0 & -3.621 & $<.001$ & .23 \\
\hline Distortions & $4.06(1-7)$ & $3.44(0-8)$ & 157.5 & -3.591 & .002 & .23 \\
\hline Omissions & $1.44(0-6)$ & $0.22(0-2)$ & 118.5 & -4.316 & $<.001$ & .33 \\
\hline Perseverations & $1.55(0-3)$ & $0.33(0-3)$ & 50.5 & -5.538 & $<.001$ & .55 \\
\hline Rotations & $0.56(0-1)$ & $0.39(0-1)$ & 212.0 & -2.625 & .009 & .12 \\
\hline Misplacements & $0.83(0-3)$ & $0.56(0-1)$ & 189.0 & -3.037 & .002 & .16 \\
\hline Time (minutes) & $9.61(6-16)$ & $9.63(6-18)$ & 231.0 & -2.270 & .023 & .09 \\
\hline
\end{tabular}




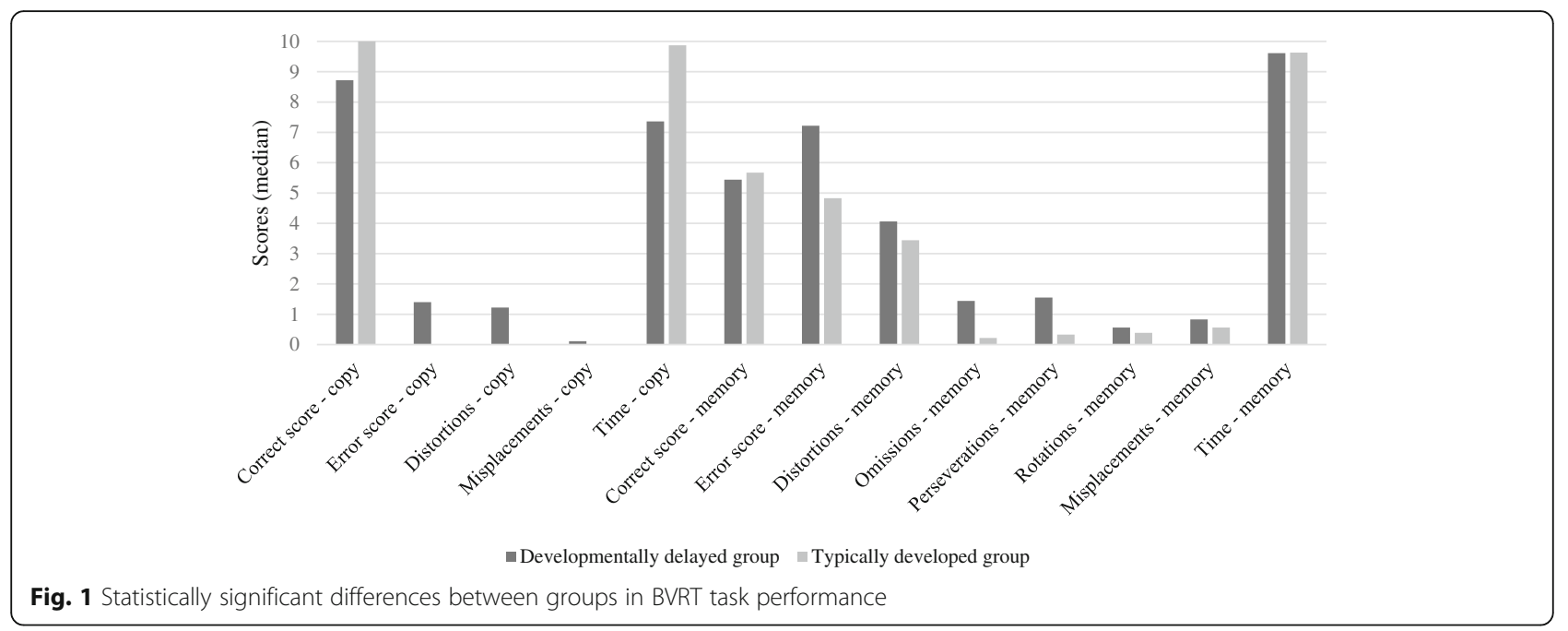

the further development of intellectual abilities in the following stages, such as school age (Leisman et al. 2015; Mecca et al. 2012). Standard neuropsychomotor development consists of progressively refined coordination of motor skills with visual-spatial abilities, specially through environmental exploration, improved planning and mental organization, and cognitive skills related to the development of higher-order cognitive skills, such as memory and executive functions, later in life (Lanca et al. 2003). In terms of visual memory, it seems that there is a dynamic interaction between cognitive function and visual perception and visual-spatial skills during development. Studies with visual-agnostic children suggested that deficits in visual-spatial skills may have an effect on visual memory performance (Metitieri et al. 2013). In this study, it is possible that children from the developmentally delayed group have more difficulties in performing a visual memory task given their deficit in basic motor and perceptual skills early in childhood.

It is important to point out that the whole sample is essentially from low socioeconomic status families. Previous publications with this longitudinal data reported that socioeconomic conditions and maternal mental health were associated with language (Piccolo et al., 2012), memory and executive function performance, and stress (Piccolo et al. 2016). Studies have reported that environmental-such as socioeconomic status, home language environment, parental style, parental mental health-and biological factors-cortisol and neurotransmitter levels, for example-may influence the typical sequence of child development, affecting cognitive abilities (Brito \& Noble, 2014; Johnson et al. 2016; Noble et al., 2015). The stimulation of sensorimotor abilities in the first years of life seems to be crucial for the development of subsequent cognitive skills (Hernandez \&
Caçola, 2015; Tierney \& Nelson, 2009). Several factors may have an effect in cognitive development, such as low birth weight; respiratory, neurological, and cardiovascular disorders; neonatal infections; malnutrition; low socioeconomic status; and prematurity, for example (Avants et al., 2015; Greenough \& Black, 2013; Handal et al. 2007). The more negative factors in the children's life, the more likely the damages in their development (Evans \& Fuller-Rowell, 2013).

The first years of life are the period of greater brain plasticity (Markham \& Greenough, 2004; Wachs et al. 2014), and the activities carried out in this phase support the integration between the different sensory sources, facilitating the emergence of adaptive responses to different situations, which forms the basis for the acquisition of mental and social skills (Leisman et al., 2015). Children living in deprived environments are more susceptible to adverse environmental conditions such as toxins, chronic malnutrition, nutrient deficiency, and lack of stimulation, leading to a higher risk of neurological and behavioral disorders, such as learning disabilities and intellectual deficit later in life (Handal et al., 2007; Johnson et al., 2016). Given that the groups assessed in this study were composed of children from low SES families, the socioeconomic factors may have limited sensorimotor experiences in early childhood. It is hypothesized that these limitations in an extremely important period for child development, combined with limited access to materials and suitable conditions for the development of the child, could not be compensated for up to school age for this study's sample. It has been pointed out also the need to deepen the study of environmental variables (Lipina \& Segretin, 2015), as other factors such as language environment at home (Melvin et al., 2016), absence of a parent (McLanahan et al. 2013), or stress as a result of living in disadvantaged 
environments (Callaghan \& Tottenham, 2016; Evans \& Fuller-Rowell, 2013; Piccolo et al., 2016) may have short- and long-term effects in child development.

One can ask: if all children are from low SES environments, why do some of them have presented deficits but some of them have not? Some hypotheses were formulated to answer this question. First, there are genetic factors that may determine at least a significant amount of those cognitive skills and deficits (Krapohl et al., 2014), and it may vary from children to children. Then, there are other variables that can be involved such as distinct pedagogical practice approach from different schools (Bondy et al. 2007; Challen et al. 2014; Malti et al. 2011), parenting style (Karbach et al. 2013; Lugo-Gil \& Tamis-LeMonda, 2008), and environmental nurturing (Avants et al., 2015; McEwen, 2012). Some mechanisms of resilience may underline these results as well (Chen et al., 2012; Hutz et al. 1996). Finally, all those hypothesized dimensions may be involved and impact on children development through a mechanism explored by social sciences called the "Matthew effect" or "accumulated advantage" (Mellard et al. 2012; Stanovich, 1986). According to this theory, individuals who have better developmental conditions develop better skills, which in turn improve their environment, creating a beneficial cumulative effect. On the other hand, those individuals from more disadvantaged environments who already present a deficit, specially a difficulty in the important dimension of functionality, may not be able to overcome these difficulties once the environment is not stimulating enough and the opportunities of better life conditions (such as high-quality schools and safe neighborhoods) are scarce, limited, or insufficient, creating a cycle of maladaptation that becomes harder to cope with.

Studies about the effect of early life experiences, its effects on development, and the mechanisms that underlie those associations still have a lot of questions to answer, and this research provides additional evidences in this sense. The strengths of this study include the analysis of a longitudinal sample, which allows inferring data on child development along different stages, although not causal relationships. In addition, this study contributes to the comprehension of how events that occur in the first years of life are essential for understanding the later development. Results from this study draw attention to the importance of early development evaluation to identify children with delays and start intervention as soon as those deficits are detected. The findings of this study have implications for intervention programs as well. First, it seems that the best strategy is to start the intervention early in childhood, as it was already reported in studies from social and economic sciences showing that early developmental delay prevention significantly reduces future costs in treatments (Belfield et al. 2006; Heckman, 2000; Reynolds et al. 2011). Second, it implies that interventions targeting children who grow up in disadvantaged environments may create opportunities for them to overcome those environmental limitations and achieve better cognitive outcomes.

It is important to mention that our findings can only indicate correlational association between the variables in those two different periods of children's development. Although this study had a longitudinal design, we cannot infer casual effects of the variables from early childhood on the differences in visual-constructive skills later on at school age, since other variables (biological, behavioral, or socioeconomic) may contribute to the outcomes. Future studies aim to surpass some limitations of this work, expanding the sample size and investigating further factors of resilience and childhood development protection.

\section{Conclusions}

This study pointed out an important association between neuropsychomotor development at early childhood and children's visual-constructive skills at school age. Those findings call attention to the importance of early evaluation of children's development. Delays in child development trigger a complex and damaging cycle for the development of the child with such deficits. Consequently, it is necessary to evaluate and understand the cognitive processing in preschoolers in detail, taking into account family and school relationships, as well as its impact on the child's adaptive functioning. Complete neuropsychological assessment enables early identification of children's preserved and affected abilities. As a consequence, it is possible to delineate effective early interventions and likely help children reach better outcomes.

\section{Authors' contributions \\ LRP conceived the study, analyzed the data, participated in its design, and wrote the manuscript. JDS helped to analyze the data, participated in the design of the study, and helped to write the manuscript. OGF, CLCF, DRB, $\mathrm{CMT}$, and $\mathrm{CH}$ participated in the study design and coordination and helped to write the manuscript. JFS conceived the study, participated in its design and coordination, and helped to write the manuscript. All authors read and approved the final manuscript.}

\section{Competing interests}

The authors declare that they have no competing interests.

\section{Ethics approval and consent to participate}

This study was approved by the Ethics Committee of the Hospital de Clínicas de Porto Alegre (number 08073/2008).

\section{Author details}

'Departamento de Psicologia, Universidade Federal do Rio Grande do Sul (UFRGS), Rua Ramiro Barcellos, 2600, 90035-003 Porto Alegre, RS, Brazil.

Departamento de Psiquiatria e Medicina Legal, UFRGS, Rua Ramiro Barcelos 2350, 90035-903 Porto Alegre, RS, Brazil. ${ }^{3}$ Grupo Hospitalar Conceição, Av. Francisco Trein, 596, 91350-200 Porto Alegre, RS, Brazil. 
Received: 14 July 2016 Accepted: 8 September 2016 Published online: 18 September 2016

\section{References}

Accardo, P. J., Accardo, J. A., \& Capute, A. J. (2008). A neurodevelopmental perspective on the continuum of developmental disabilities. (3rd ed. Vol. I). Baltimore: Paul $\mathrm{H}$ Brookes Publishing.

Ali, S. S. (2013). A brief review of risk-factors for growth and developmental delay among preschool children in developing countries. Advanced Biomedical Research, 2, 91. doi:10.4103/2277-9175.122523.

Allen, L. R., \& Kelly, B. B. (2015). Transforming the workforce for children birth through age 8: a unifying foundation. Washington, DC: National Academies Press (US).

Amaral, A. C. T., Tabaquim, M. L. M., \& Lamônica, D. A. C. (2005). Avaliação das habilidades cognitivas, da comunicação e neuromotoras de crianças com risco de alterações do desenvolvimento. Revista Brasileira de Educação Especial, 11(2), 185-200.

Avants, B. B., Hackman, D. A., Betancourt, L. M., Lawson, G. M., Hurt, H., \& Farah, M. J. (2015). Relation of childhood home environment to cortical thickness in late adolescence: specificity of experience and timing. PloS One, 10(10), e0138217. doi:10.1371/journal.pone.0138217.

Bart, O., Hajami, D., \& Bar-Haim, Y. (2007). Predicting school adjustment from motor abilities in kindergarten. Infant and Child Development, 16(6), 597-615. doi:10.1002/icd.514.

Belfield, C. R., Nores, M., Barnett, W. S., \& Schweinhart, L. J. (2006). The High/Scope Perry Preschool Program: cost-benefit analysis using data from the age-40 followup. Journal of Human Resources, 41(1), 162-190. doi:10.3368/jhr.XLI.1.162.

Bondy, E., Ross, D. D., Gallingane, C., \& Hambacher, E. (2007). Creating environments of success and resilience: culturally responsive classroom management and more. Urban Education, 42(4), 326-348. doi:10.1177/ 0042085907303406

Brito, N. H., \& Noble, K. G. (2014). Socioeconomic status and structural brain development. Frontiers in Neuroscience, 8, 276. doi:10.3389/fnins.2014.00276.

Callaghan, B. L., \& Tottenham, N. (2016). The neuro-environmental loop of plasticity: a cross-species analysis of parental effects on emotion circuitry development following typical and adverse caregiving. Neuropsychopharmacology, 41(1), 163-176. doi:10.1038/npp.2015.204.

Casey, B. J., Galvan, A., \& Hare, T. A. (2005). Changes in cerebral functional organization during cognitive development. Current Opinion in Neurobiology, 15(2), 239-244. doi:10.1016/j.conb.2005.03.012

Challen, A. R., Machin, S. J., \& Gillham, J. E. (2014). The UK Resilience Programme: a school-based universal nonrandomized pragmatic controlled trial. Journal of Consulting and Clinical Psychology, 82(1), 75-89. doi:10.1037/a0034854.

Chen, C. H., Gutierrez, E. D., Thompson, W., Panizzon, M. S., Jernigan, T. L., Eyler, L. T., Dale, A. M. (2012). Hierarchical genetic organization of human cortical surface area. Science, 335(6076), 1634-1636. doi:10.1126/science.1215330

Corso, H. V. (2007). Dificuldades de aprendizagem e atrasos maturativos: atenção aos aspectos neuropsicomotores na avaliação e terapia psicopedagógicas. Revista Psicopedagogia, 24(73), 76-89.

Davis, N. M., Ford, G. W., Anderson, P. J., \& Doyle, L. W. (2007). Developmental coordination disorder at 8 years of age in a regional cohort of extremelylow-birthweight or very preterm infants. Developmental Medicine and Child Neurology, 49(5), 325-330. doi:10.1111/j.1469-8749.2007.00325.x.

de Moura, D. R., Costa, J. C., Santos, I. S., Barros, A. J. D., Matijasevich, A., Halpern, R., Dumith, S., Karam, S., \& Barros, F. C. (2010). Risk factors for suspected developmental delay at age 2 years in a Brazilian birth cohort. Paediatric and Perinatal Epidemiology, 24, 211-221. doi:10.1111/j.1365-3016.2010.01115.x.

Dornelas, L. F., Duarte, N. M. C., \& Magalhães, L. C. (2015). Neuropsychomotor developmental delay: conceptual map, term definitions, uses and limitations. Revista Paulista de Pediatria, 33(1), 88-103. doi:10.1016/j.rpped.2014.04.009.

Drachler, M. L., Marshall, T., \& de Carvalho Leite, J. C. (2007). A continuous-scale measure of child development for population-based epidemiological surveys: a preliminary study using Item Response Theory for the Denver Test. Paediatric and Perinatal Epidemiology, 21(2), 138-153. doi:10.1111/j.1365-3016. 2007.00787.x.

Evans, G. W., \& Fuller-Rowell, T. E. (2013). Childhood poverty, chronic stress, and young adult working memory: the protective role of self-regulatory capacity. Developmental Science, 16(5), 688-696. doi:10.1111/desc.12082.

Falceto, O. G., Busnello, E. D., \& Bozzetti, M. C. (2000). Validação de escalas diagnósticas do funcionamento familiar para utilização em serviços de atenção primária à saúde. Revista Panamericana de Salud Pública, 7(4), 255263. doi:10.1590/S1020-49892000000400007.

Frankenburg, W. K., Dodds, J., Archer, P., Shapiro, H., \& Bresnick, B. (1992). The Denver II: a major revision and restandardization of the Denver Developmental Screening Test. Pediatrics, 89(1), 91-97.

Grantham-McGregor, S., Cheung, Y. B., Cueto, S., Glewwe, P., Richter, L., Strupp, B., \& International Child Development Steering Group. (2007). Developmental potential in the first 5 years for children in developing countries. Lancet, 369(9555), 60-70. doi:10.1016/50140-6736(07)60032-4.

Greenough, W. T., \& Black, J. E. (2013). Induction of brain structure by experience: substrates for cognitive development. In M. R. Gunnar \& C. A. Nelson (Eds.), Developmental behavioral neuroscience (Vol. 24). New York, NY: Routledge.

Groth-Marnat, G. (2009). Handbook of psychological assessment (5th ed.). Hoboken NJ: Wiley.

Handal, A. J., Lozoff, B., Breilh, J., \& Harlow, S. D. (2007). Sociodemographic and nutritional correlates of neurobehavioral development: a study of young children in a rural region of Ecuador. Pan American Journal of Public Health, 21(5), 292-300. doi:10.1590/S1020-49892007000400004.

Heckman, J. J. (2000). Policies to foster human capital. Research in Economics, 54(1), 3-56. doi:10.1006/reec.1999.0225.

Hernandez, A. M., \& Caçola, P. (2015). Motor proficiency predicts cognitive ability in four-year-olds. European Early Childhood Education Research Journal, 23(4), 573-584. doi:10.1080/1350293X.2014.991094.

Hutz, C., Koller, S. H., \& Bandeira, D. R. (1996). Resiliência e vulnerabilidade em crianças em situação de risco. Coletâneas da ANPEPP, 1(12), 79-86.

Iverson, J. M. (2010). Developing language in a developing body: the relationship between motor development and language development. Journal of Child Language, 37(2), 229-261. doi:10.1017/S0305000909990432.

Johnson, S. B., Riis, J. L., \& Noble, K. G. (2016). State of the art review: poverty and the developing brain. Pediatrics, 137(4), e20153075. doi:10.1542/peds. 2015-3075.

Karbach, J., Gottschling, J., Spengler, M., Hegewald, K., \& Spinath, F. M. (2013). Parental involvement and general cognitive ability as predictors of domainspecific academic achievement in early adolescence. Learning and Instruction, 23, 43-51. doi:10.1016/j.learninstruc.2012.09.004

Krapohl, E., Rimfeld, K.i, Shakeshaft, N. G., Trzaskowski, M., McMillan, A., Pingault, J., Plomin, R. (2014). The high heritability of educational achievement reflects many genetically influenced traits, not just intelligence. Proceedings of the National Academy of Sciences, 111(42), 15273-15278. doi:10.1073/pnas.1408777111

Lanca, M., Jerskey, B. A., \& O'Connor, M. G. (2003). Neuropsychologic assessment of visual disorders. Neurologic Clinics, 21(2), 387-416. doi:10.1016/S07338619(02)00109-3.

Le Boulch, J. (2001). O desenvolvimento psicomotor: do nascimento até os 6 anos. Porto Alegre, RS: Artes Médicas.

Leisman, G., Mualem, R., \& Mughrabi, S. K. (2015). The neurological development of the child with the educational enrichment in mind. Psicología Educativa, 21(2), 79-96. doi:10.1016/j.pse.2015.08.006.

Levey, S., \& Polirstok, S. (2011). Language development: understanding language diversity in the classroom. Thousand Oaks, CA: Sage.

Lipina, S. J., \& Segretin, M. S. (2015). Strengths and weakness of neuroscientific investigations of childhood poverty: future directions. Frontiers in Human Neuroscience, 9, 53. doi:10.3389/fnhum.2015.00053.

Lipkin, P. H., \& Schertz, M. (2008). Early intervention. In P. J. Accardo (Ed.), Capute and Accardo's neurodevelopmental disabilities in infancy and childhood (Vol. I pp. 519-552). Baltimore: Paul H Brookes Publishing.

Lugo-Gil, J., \& Tamis-LeMonda, C. S. (2008). Family resources and parenting quality: links to children's cognitive development across the first 3 years. Child Development, 79(4), 1065-1085. doi:10.1111/j.1467-8624.2008.01176.x.

Malti, T., Ribeaud, D., \& Eisner, M. P. (2011). The effectiveness of two universal preventive interventions in reducing children's externalizing behavior: a cluster randomized controlled trial. Journal of Clinical Child \& Adolescent Psychology, 40(5), 677-692. doi:10.1080/15374416.2011.597084.

Mari, J. J., \& Williams, P. (1986). A validity study of a psychiatric screening questionnaire (SRQ-20) in primary care in the city of Sao Paulo. The British Journal of Psychiatry, 148(1), 23-26. doi:10.1192/bjp.148.1.23.

Markham, J. A., \& Greenough, W. T. (2004). Experience-driven brain plasticity: beyond the synapse. Neuron Glia Biology, 1(4), 351-363. doi:10.1017/ s1740925x05000219.

MARPLAN (2008). Dados consolidados 2008 - Grupo de mídia de São Paulo. Recuperado em 23 de fevereiro, 2010, do http://www.ipsos.com.br. 
Metitieri, T., Barba, C., Pellacani, S., Viggiano, M. P., \& Guerrini, R. (2013). Making memories: the development of long-term visual knowledge in children with visual agnosia. Neural Plasticity, 2013, 306432. doi:10.1155/2013/306432.

McEwen, B. S. (2012). Brain on stress: how the social environment gets under the skin. Proceedings of the National Academy of Sciences, 109, 17180-17185. doi:10.1073/pnas.1121254109

McLanahan, S., Tach, L., \& Schneider, D. (2013). The causal effects of father absence. Annual Review of Sociology, 399, 399-427. doi:10.1146/annurev-soc071312-145704

Mecca, T. P., Antonio, D. A. M., \& Macedo, E. C. (2012). Desenvolvimento da inteligência em pré-escolares: implicações para a aprendizagem. Revista Psicopedagogia, 29(88), 66-73.

Mellard, D. F., Frey, B. B., \& Woods, K. L. (2012). School-wide student outcomes of response to intervention frameworks. Learning Disabilities - A Contemporary Journal, 10(2), 17-32.

Melvin, S. A., Brito, N. H., Mack, L. J., Engelhardt, L. E., Fifer, W. P., Elliott, A. J., \& Noble, K. G. (2016). Home environment, but not socioeconomic status, is linked to differences in early phonetic perception ability. Infancy. doi:10.1111/infa.12145.

Murray, G. K., Jones, P. B., Kuh, D., \& Richards, M. (2007). Infant developmental milestones and subsequent cognitive function. Annual Neurology, 62(2), 128-136. doi:10.1002/ana.21120.

Murray, G. K., Veijola, J., Moilanen, K., Miettunen, J., Glahn, D. C., Cannon, T. D., Isohanni, M. (2006). Infant motor development is associated with adult cognitive categorisation in a longitudinal birth cohort study. Journal of Child Psychology and Psychiatry, 47(1), 25-29. doi:10.1111/j.1469-7610.2005.01450.x

Noble, K. G., Engelhardt, L. E., Brito, N. H., Mack, L. J., Nail, E. J., Angal, J., Elliott, A. J. (2015). Socioeconomic disparities in neurocognitive development in the first two years of life. Developmental Psychobiology, 57(5), 535-551. doi:10.1002/dev.21303

Piccolo, L. R., Falceto, O. G., Fernandes, C. L., Levandowski, D. C., Grassi-Oliveira, R. \& Salles, J. F. (2012). Variáveis psicossociais e desempenho em leitura de crianças de baixo nível socioeconômico. Psicologia: Teoria e Pesquisa, 28(4), 389-398. doi:10.1590/S0102-37722012000400004.

Piccolo, L. R., Salles, J. F., Falceto, O. G., Fernandes, C. L., \& Grassi-Oliveira, R. (2016). Can reactivity to stress and family environment explain memory and executive functions performance in early and middle childhood? TRENDS in psychiatry and psychotherapy, 38(2), 567-575. doi:10.1590/2237-6089-2015-0085.

Prelock, P. A., Hutchins, T., \& Glascoe, F. P. (2008). Speech-language impairment: how to identify the most common and least diagnosed disability of childhood. The Medscape Journal of Medicine, 10(6), 136.

Reynolds, A. J., Temple, J. A., White, B. A. B., Ou, S., \& Robertson, D. L. (2011). Age 26 cost-benefit analysis of the child-parent center early education program. Child Development, 82(1), 379-404. doi:10.1111/j.1467-8624.2010.01563.x.

Salles, J. F., Bandeira, D. R., Trentini, C. M., Segabinazi, J. D., \& Hutz, C. S. (2016). Teste Retenção Visual de Benton. São Paulo, SP: Vetor.

Segabinazi, J. D., Duarte-Junior, S., Salles, J. F., Bandeira, D. R., Trentini, C. M., \& Hutz, C. S. (2013). Teste de Retenção Visual de Benton: apresentação do manual brasileiro. Avaliação Psicológica, 12, 421-428

Skaliora, I. (2002). Experience-dependent plasticity in the developing brain. International Congress Series, 1241, 313-320. doi:10.1016/S0531-5131(02)00616-7.

Stanovich, K. E. (1986). Matthew effects in reading: some consequences of individual differences in the acquisition of literacy. Reading Research Quarterly, 22, 360-407.

Taanila, A., Murray, G. K., Jokelainen, J., Isohanni, M., \& Rantakallio, P. (2005). Infant developmental milestones: a 31-year follow-up. Developmental Medicine \& Child Neurology, 47(9), 581-586.

Theuer, R. V., \& Flores-Mendoza, C. E. (2003). Avaliação da inteligência na primeira infância. PsicoUSF, 8, 21-32.

Tierney, A. L., \& Nelson, C. A. (2009). Brain development and the role of experience in the early years. Zero to three, 30(2), 9-13.

Trentini, C. M., Yates, D. B., \& Heck, V. S. (2014). Escala Wechsler Abreviada de Inteligência - WASI. São Paulo, SP: Casa do Psicólogo.

Wachs, T. D., Georgieff, M., Cusick, S., \& McEwen, B. S. (2014). Issues in the timing of integrated early interventions: contributions from nutrition, neuroscience, and psychological research. Annals of the New York Academy of Sciences, 1308(1), 89-106. doi:10.1111/nyas.12314.

Wendt, L., Mäkinen, H., \& Rantakallio, P. (1984). Psychomotor development in the first year and mental retardation-a prospective study. Journal of Intellectual Disability Research, 28(3), 219-225. doi:10.1111/j.1365-2788.1984.tb01013.x.

Yates, D. B., Trentini, C. M., Tosi, S. D., Corrêa, S. K., Poggere, L. C., \& Valli, F. (2006). Apresentação da Escala de Inteligência Wechsler abreviada: (WASI). Avaliação Psicológica, 5, 227-233.

\section{Submit your manuscript to a SpringerOpen ${ }^{\circ}$ journal and benefit from:}

- Convenient online submission

- Rigorous peer review

- Immediate publication on acceptance

- Open access: articles freely available online

- High visibility within the field

- Retaining the copyright to your article

Submit your next manuscript at $>$ springeropen.com 